\title{
A articulação entre conhecimento tácito e inovação tecnológica: a função mediadora da educação
}

\author{
Acácia Zeneida Kuenzer \\ Claudia Barcelos de Moura Abreu
}

Universidade Federal do Paraná, Setor de Educação

\author{
Cristiano Mauro Assis Gomes \\ Universidade Federal de Minas Gerais, Faculdade de Filosofia e Ciências Humanas
}

\section{Introdução}

O presente texto tem como objetivo apresentar os principais resultados e análises oriundos de uma pesquisa realizada em empresa do setor petroquímico brasileiro que iniciou processo de mudança tecnológica em uma planta industrial. ${ }^{1}$ Os impactos no processo de trabalho advindos das mudanças em curso referem-se ao conjunto da força de trabalho, embora com níveis diferenciados. Isso significa que distintos grupos de profissionais sofrerão impactos mais diretos enquanto outros estarão mais distantes da operação da nova tecnologia, mas é possível afirmar que todo o ambiente de trabalho sofrerá alterações provenientes da mudança.

As transformações tecnológicas que vêm ocorrendo no mundo do trabalho apresentam um amplo

${ }^{1}$ As informações levantadas com a pesquisa de campo foram organizadas e tratadas pelo pesquisador júnior Rafael Carlos dos Santos, acadêmico do curso de engenharia da produção da Pontifícia Universidade Católica do Paraná (PUC-PR). leque de modificações no processo de produção e na forma de organização do trabalho. Elas geram um clima de incertezas e desafios para a sociedade e para os trabalhadores diretamente impactados. Considerando que a mudança tecnológica em curso faz uso intensivo de tecnologia microeletrônica e demanda conhecimentos científicos por parte dos operadores, a questão norteadora para os trabalhadores está relacionada aos níveis de exigência desses novos conhecimentos, assim como o modo como seriam feitas as readequações necessárias em um contexto de mudança.

A mudança em curso diz respeito a uma nova tecnologia que será utilizada para realizar a movimentação e o posicionamento da planta industrial, o que implica, do ponto de vista do investimento, mais rapidez e maiores estabilidade e confiabilidade para processar as operações.

\section{A pesquisa e o perfil da força de trabalho}

A pesquisa desenvolveu-se a partir de entrevistas realizadas com os trabalhadores ligados direta- 
mente à empresa petroquímica, ${ }^{2}$ totalizando 91 entrevistas, ${ }^{3}$ o que representa a totalidade da força de trabalho da empresa naquela planta. $\mathrm{O}$ instrumento de pesquisa foi construído após reuniões com os coordenadores do processo de modernização da planta. A partir dos pontos indicados pelo grupo gestor, a equipe de pesquisadores demarcou o número de 30 questões e um tempo, em torno do duas horas, para cada entrevistado. As questões do instrumento procuravam caracterizar as atividades desenvolvidas pelos trabalhadores, os conhecimentos necessários, os processos de capacitação em serviço, o perfil formativo e obter reflexões sobre as mudanças em curso e as disposições para o enfrentamento dos novos desafios postos.

Com relação ao processo de trabalho, há uma divisão das atividades executadas na planta em três áreas distintas: operação, manutenção e administração. Os grupos diretamente impactados pelas mudanças são os operadores e o pessoal da manutenção; o grupo de operadores ligados às atividades de posicionamento será responsável pelo uso da nova tecnologia e os trabalhadores da manutenção serão diretamente confrontados com novos equipamentos e sistemas.

Em termos quantitativos, os 91 trabalhadores da planta estão divididos da seguinte forma:

Tabela 1 - Distribuição da força de trabalho nos setores

\begin{tabular}{|l|c|c|c|c|}
\hline Setor & Operação & Manutenção & Administração & Total \\
\hline Trabalhadores & 40 & 34 & 17 & 91 \\
\hline
\end{tabular}

Fonte: Pesquisa realizada na empresa petroquímica.

${ }^{2}$ A empresa possui trabalhadores contratados diretamente e subcontrata trabalhadores por meio de contratos com outras empresas. Às vezes, o número de funcionários subcontratados é maior do que o do efetivo da empresa. Neste caso, foram coletados dados apenas dos trabalhadores diretos.

${ }^{3}$ As entrevistas foram realizadas ao longo de um mês em diferentes locais: na sede da empresa, em universidade, no local de trabalho.
No que diz respeito à escolarização, há por parte da empresa a exigência de grau de escolaridade média, sendo que grande parte dos trabalhadores realizou estudos no curso médio técnico, poucos possuem ensino médio propedêutico e outros possuem curso superior.

Tabela 2 - Escolarização da força de trabalho

\begin{tabular}{|l|c|c|c|c|}
\hline $\begin{array}{l}\text { Nível de } \\
\text { escolaridade }\end{array}$ & $\begin{array}{c}\text { Médio } \\
\text { propedêutico }\end{array}$ & $\begin{array}{c}\text { Médio } \\
\text { técnico }\end{array}$ & Superior & Total \\
\hline Trabalhadores & 18 & 44 & 29 & 91 \\
\hline
\end{tabular}

Fonte: Pesquisa realizada na empresa petroquímica.

É possível observar que o perfil de escolaridade da força de trabalho aqui apresentada tem uma característica peculiar em relação à média da força de trabalho industrial brasileira: enquanto se registra uma média de escolaridade de 7,4 anos (Sabóia, 2001) para o conjunto da força de trabalho, os sujeitos da pesquisa possuem no mínimo 11 anos de escolarização.

Outro fato importante para compreendermos o perfil dos pesquisados diz respeito ao grau de organização dessa categoria profissional, cujo sindicato é marcado por uma atuação fortemente classista, o que significa que, ao longo do processo de modernização da planta, os direitos adquiridos não deverão ser contestados. Isso posto, verifica-se que as transformações em processo estão articuladas às mudanças na qualificação e talvez nos postos de trabalho, mas não em relação ao emprego.

Na tentativa de explicitar as especificidades desse grupo de profissionais, é importante relatar também que o local de trabalho é um ambiente especial, cuja jornada de trabalho possui um cronograma de 14 dias de trabalho e 21 dias de descanso; está sujeito às intempéries das condições ambientais que determinam início e abandono das operações, condições que o homem pode prever mas não modificar; todos os mantimentos, equipamentos e ferramentas devem ser transportados até a planta, o que implica mobilização da mão-de-obra e da planta industrial não apenas para operar, executar tarefas planejadas pela sede em terra, mas também para executar tarefas de manutenção da planta para as atividades do dia-a-dia. 
Além da característica da jornada de trabalho, é necessário acrescentar que os trabalhadores residem em diferentes pontos do território nacional, o que ocasiona distanciamento entre eles e entre eles e a sede da empresa durante o período de descanso.

Como último ponto, é necessário acrescentar que a política de capacitação da empresa apresenta um leque amplo de possibilidades de especialização. É possível perceber, pelo histórico de cursos dos trabalhadores, que os treinamentos são freqüentes, mas vêm caracterizando-se, segundo os depoimentos dos trabalhadores, por apresentar conteúdos com características marcadamente atitudinais. Esse aspecto tem impactado negativamente os trabalhadores, pois estes compreendem seu trabalho pela óptica da operação, ou seja, entendem que as atividades que executam têm natureza marcadamente técnica e é por essa perspectiva que entendem que se dá a capacitação.

\section{A relação entre conhecimento tácito e científico na base microeletrônica}

A análise do perfil dos trabalhadores, ao relacionar idade, tempo de trabalho na planta e escolaridade, indica uma primeira relação relevante entre conhecimento tácito e científico: a idade dos empregados (77\% dos trabalhadores têm mais de 40 anos), articulada ao tempo de trabalho (50\% têm mais de 10 anos de experiência na planta), configura uma força de trabalho integrada por muitos empregados que, em virtude de sua longa experiência laboral, acumularam expressivo e indispensável conhecimento sobre o trabalho.

Se tomarmos dez anos como ponto de corte, os dados revelam a convivência entre trabalhadores experientes e trabalhadores novos, meio a meio. Esses dados adquirem significado quando cruzados com a escolaridade, evidenciando que os mais antigos se caracterizam pela primazia do conhecimento tácito sobre o científico e pela ausência, de modo geral, de relação sistematizada com o conhecimento por meio de cursos de mais longa duração em períodos mais recentes. São profissionais que fizeram sua qualifica- ção no passado, em grande parte em cursos com alguma aderência ao trabalho que realizam, mas que não voltaram a estudar de forma mais continuada, embora tenham freqüentado cursos específicos de capacitação profissional e nem sempre aderentes ao exercício de suas funções. No entanto, esses trabalhadores, dada a especificidade da planta, desenvolveram pela experiência competências tácitas ${ }^{4}$ que certamente impactam significativamente a produtividade e a qualidade do trabalho.

Os mais novos, por sua vez, caracterizam-se por ter mais domínio teórico do que prático, em função de suas trajetórias de formação escolar mais recentes, em muitos casos em nível superior e, em alguns, em nível de pós-graduação.

De qualquer modo, todos, sem exceção, reportam que aprenderam a trabalhar na planta trabalhando. Dadas as especificidades do trabalho de operação, não há cursos disponíveis para capacitação nessa especialidade. Segundo os relatos dos mais antigos, sequer houve preparação prévia; chegavam e começavam a trabalhar, aprendendo com os mais experientes, observando, perguntando, experimentando, acertando e errando. Em decorrência, acumularam um conhecimento tácito que, por guardar pouca relação com a formação anterior, não é passível de sistematização, e, conseqüentemente, de transmissão por processos formalizados de ensino. Nesses casos, o ensino pelos mais experientes ocorre por tutoria, com foco nas formas de fazer. Como o trabalho da operação é simplificado e repetitivo, oferece reduzidas oportunidades de qualificação, sendo apontado como "desqualificante" pela maioria dos entrevistados, muitos dos quais afirmam que "desaprenderam" ao longo do pro-

${ }^{4}$ Conhecimentos e competências tácitas são as adquiridas pela experiência; pelo seu caráter prático, não são passíveis de sistematização teórica, e em função disso não podem ser ensinadas; seu desenvolvimento depende da subjetividade, das oportunidades de acesso à informação, das oportunidades de trabalho, da cultura, das relações sociais vividas por cada trabalhador. São desenvolvidas, e não adquiridas em processos sistematizados de ensino. 
cesso. Contraditoriamente, revelam amplo domínio de formas de fazer que lhes permitem diagnosticar e resolver problemas de diferentes níveis de complexidade, mas sempre a partir das experiências anteriores.

Por seu caráter prático, simplificado e pouco dinâmico do ponto de vista das inovações, esse conhecimento tácito não se ancora na teoria, é marcado por seu caráter eminentemente prático; refere-se às práticas rotineiras que se desenvolvem sem apoio na teoria. Isso não significa afirmar que esse conhecimento tácito não seja relevante; ao contrário, é ele que assegura a normalidade e a segurança da planta nas suas atividades cotidianas. $\mathrm{O}$ que se pretende demarcar é o seu caráter prático, psicofísico, porquanto mediado pela corporeidade, como se vai discutir mais adiante.

Os operadores mais novos, detentores de formação teórica mais adensada, passam pelo mesmo processo de aprendizagem na prática e através dela, com apoio na experiência dos mais velhos, embora reportem o uso dos manuais e procedimentos como recursos de apoio. Contudo, as entrevistas feitas com esse grupo permitem evidenciar que a pouca aderência entre formação e operação da planta os leva mais a fazer uso das competências cognitivas complexas desenvolvidas ao longo da trajetória de escolaridade do que acessar conhecimentos teóricos. Tal afirmação tem apoio na inexistência de pré-requisitos de formação escolar para aprender a operação; qualquer trabalhador pode aprender a operar, desde que se empenhe para fazê-lo; no caso analisado, é a experiência integrada ao tempo que ensina. Daí o caráter predominantemente tácito do conhecimento dos operadores; eles refletem e raciocinam, processo no qual integram conhecimentos e experiências anteriores, na prática e a partir dela.

Essa realidade caracteriza o primeiro desafio apontado pela investigação: o conhecimento tácito, típico das formas tayloristas/fordistas de organizar o trabalho, é relevante nos processos de trabalho cuja base técnica é a microeletrônica? Ou é dispensável? No caso em estudo, ele exerce alguma função na aprendizagem das novas tecnologias ou pode ser des- cartado? Os operadores que apresentam esse perfil devem ser mantidos ou devem ser substituídos por novos trabalhadores que tenham domínio científicotecnológico mais avançado, o que a princípio facilitaria o processo de capacitação, assegurando o desenvolvimento das competências necessárias para operar com segurança e confiabilidade?

Para responder a esse desafio torna-se necessário elucidar a permanência do conhecimento tácito nos processos automatizados, posto que há uma tendência a eximir as formas modernas de trabalho industrial de qualquer possibilidade de utilização de competência prática significativa. ${ }^{5}$ Contrariando essa tendência, Jones e Wood apontam para a necessidade de compreender melhor a relação entre conhecimento tácito e novas tecnologias, considerando que aquele se insere no âmbito das dimensões subjetivas do trabalho, formas inconscientes e geralmente não reconhecidas, pelas quais os trabalhadores, mesmo desqualificados, utilizam um saber com amplo poder de intervenção nos trabalhos prescritos (Jones \& Wood, 1984, tradução livre).

No taylorismo/fordismo é esse saber que torna possível a execução das tarefas em face das diferenças entre trabalho prescrito e trabalho real, em razão do que o capital permanece em significativa dependência do trabalho, a partir do que reforça o poder de negociação dos trabalhadores. Nesse sentido, a automação, ao transferir para a máquina o trabalho e também seu controle, permite ao mesmo tempo diminuir essa dependência, melhorar a confiabilidade do sistema e auferir ganhos de produtividade em vista dos desafios da competitividade; e, de quebra, diminuir o poder dos trabalhadores.

Resta saber se a independência em relação ao conhecimento tácito é possível a partir da automação. Tomaremos aqui três pesquisas que evidenciam o oposto, com a finalidade apenas de levantar hipóteses para a investigação acerca da relação entre co-

${ }^{5}$ Esse tema foi tratado de modo mais ampliado por Kuenzer (2003). 
nhecimento tácito e científico em face das novas tecnologias: a realizada por Jones e Wood (1984) sobre a relação entre qualificações tácitas e novas tecnologias; a desenvolvida por Llori (2001), que estuda o fator humano nos grandes acidentes industriais ocorridos na década de 1980; a realizada por Dejours (1993), também sobre as dimensões subjetivas do trabalho (Jones \& Wood, 1984; Llori, 2001).

Todos esses autores são enfáticos ao afirmar, a partir de extensos trabalhos empíricos, que o conhecimento tácito exerce influência vital sobre a introdução e sobre o funcionamento dos sistemas mediados pela base microeletrônica. Inicialmente, mostram Jones e Wood, a implantação de novas técnicas e novos equipamentos depende do conhecimento existente, enraizado em uma prática anterior bem-sucedida (Jones \& Wood, 1984, p. 3).

Essa afirmação tem sido confirmada pelas pesquisas realizadas por Kuenzer (2003) na última década, na Região Metropolitana de Curitiba, por intermédio de entrevistas com trabalhadores que acompanharam as mudanças tecnológicas ao longo do tempo, porém ainda na base eletromecânica; como as novas tecnologias guardavam relação com as precedentes, a transferência das aprendizagens anteriores foi crucial para a instalação e o funcionamento dos novos equipamentos.

Os resultados desses estudos mostraram que o conhecimento tácito não desaparece com a implantação de novas tecnologias, particularmente com as de base microeletrônica, mas muda de qualidade, passando a exigir maior aporte de conhecimentos científicos que não podem ser obtidos somente pela prática, senão por cursos sistematizados.

Essa afirmação leva-nos a concluir, em primeiro lugar, que a implantação da nova tecnologia de posicionamento dinâmico, de base microeletrônica, a ser efetivada na planta objeto desta pesquisa, não prescinde do conhecimento tácito dos operadores mais antigos; ao contrário, os mais experientes, guardiões de um conhecimento tácito relevante, assumem papel primordial junto aos novos trabalhadores, cuja capacitação para operar os novos equipamentos de- manda conhecimento da realidade do trabalho nas suas dimensões de historicidade e de totalidade, o que significa ter experiência na planta tal como ela operou até agora como condição para apropriação adequada das novas tecnologias, necessidade esta reconhecida pelos mais novos no transcurso das entrevistas.

Em contrapartida, a apropriação de conhecimento científico-tecnológico necessário para a implantação de processos de base microeletrônica, tal como o planejado no processo de modernização da planta, demanda relação permanente e sistematizada com o conhecimento teórico pelo domínio das categorias do trabalho intelectual, característica que se mostrou presente entre os trabalhadores mais novos, que são detentores de níveis mais elevados de escolaridade.

Vista dessa forma, a relação entre conhecimento tácito e conhecimento científico na base microeletrônica não é de oposição e sim de articulação dialética, posto que são categorias que se integram nos processos de trabalho flexibilizados, nos quais a prevalência do tácito ou do científico responde à especificidade do trabalho a ser realizado por uma força de trabalho de qualificações diferenciadas que se articulam para atender às necessidades das cadeias produtivas.

Essa premissa permite compreender a competência laboral como síntese entre corporeidade e intelectualidade, de modo que supere a clássica dualidade que historicamente tem oposto essas categorias e, dessa forma, recuperar a concepção de omnilateralidade, ou seja, de integralidade do ser humano como um dos fundamentos dos processos de formação.

Enfrentar essa discussão no âmbito da relação entre conhecimento tácito e científico, corporeidade e intelectualidade, implica retomar Jones e Wood (1984) quando afirmam que há diferentes elementos e graus de conhecimento tácito. O primeiro - e não o necessariamente mais simples de ser desenvolvido diz respeito às práticas rotineiras, tanto mais eficientes quanto mais automatizadas, ou seja, quanto menos intervir a ação consciente. Do ponto de vista pedagógico, adentramos no campo dos automatismos, em que a experiência é decisiva para a aprendizagem, 
secundarizando-se a compreensão teórica, a qual, se estiver presente, o será apenas no primeiro momento das explicações que se façam necessárias para iniciar o processo; nesse caso, estamos no campo da automatização pela memorização de procedimentos físicos e mentais pela repetição, o que se constitui no elemento fundante da educação taylorista/fordista.

$\mathrm{Ou}$, como afirmam os autores citados, "para que se objetive a aquisição de um comportamento rotineiro adequado, ela deve ser um processo de integração de movimentos estandardizados e de redução de atos conscientes" (Jones \& Wood, 1984, p. 6). Essas práticas rotineiras, tais como dirigir automóvel, pilotar avião, dançar, tocar um instrumento musical, fazer cálculos mentais, digitar, implicam tal integração entre corporeidade e pensamento que permitem a realização de movimentos sem a necessidade da consciência reflexiva, na medida em que ela interrompe o fluxo contínuo e a precisão no automatismo. ${ }^{6}$

Nesses casos, a corporeidade passa a exercer papel fundamental, como mostra Dejours (1993) ao analisar o que chama inteligência prática, que distingue da inteligência cognitiva. $\mathrm{O}$ autor afirma que a primeira característica da inteligência prática é estar enraizada no corpo. Assim é que os primeiros sinais de um evento (anormalidade) passam pelos sentidos, que acusam algum desconforto: um ruído, uma vi-

${ }^{6}$ Schon (1983), com base nos estudos de Pollany, mostra que há nos conhecimentos tácitos um tipo de reflexão-na-ação diferente da reflexão sobre a ação, que não impediria necessariamente o fluxo dos automatismos, de modo que vários deles não poderiam ser considerados apenas atos mecânicos livres de aspectos artísticos, estéticos e de alta complexidade cognitiva. Da mesma maneira que há diferentes níveis de conhecimento tácito, há diferentes níveis de automatismos, alguns apenas dizendo respeito a processos cognitivos de baixa qualidade, como ocorre com os trabalhadores no taylorismo/fordismo, e outros se referindo a processos muito complexos, como o ato de pintar, de tocar um instrumento com maestria ou de diagnosticar uma doença estranha em um paciente. Esses automatismos contêm processos cognitivos muito complexos, apesar de automatizados. bração, um cheiro, desde que exista uma experiência anterior comum à situação de trabalho. É essa dimensão corpórea que distingue a inteligência prática da inteligência analítica; ${ }^{7}$ é o corpo, pela percepção, que orientará a ação, conferindo à inteligência uma direção, de modo que proceda a um rápido diagnóstico sucedido de intervenção, cuja temporalidade é inversa à de um raciocínio científico, que virá depois para verificar, operacionalizar e disseminar a prática que lhe foi sugerida pela intuição (Dejours, 1993, p. 286). É dessa forma que os operadores de refinaria, os pilotos de avião ou outros profissionais atuam, primeiro levando o sistema a uma condição segura para depois verificar a melhor forma de retornar à normalidade. No caso em estudo, os trabalhadores referem-se "ao sentimento" como a competência mobilizada para fazer diagnósticos e tomar decisões sobre, por exemplo, parar ou continuar a operação em face das condições ambientais adversas. Essas decisões são difíceis, pois continuar a operar ante a iminência de alterações na normalidade da planta significa perder o trabalho, com sérias implicações relativas a retrabalho e perda de material. Ao mesmo tempo, interromper o trabalho desnecessariamente implica perdas. Embora consultem informações disponíveis nos sistemas informatizados, segundo os operadores, "parar ou continuar depende do sentimento"; ou seja, mobiliza-se a inteligência corpórea, que integra dialeticamente as sensações, às informações, reflexões, a partir das experiências anteriores.

${ }^{7} \mathrm{O}$ termo inteligência analítica foi elaborado por Sternberg para designar que as habilidades cognitivas estudadas até o presente momento pela psicometria não respondem pela diversidade de estruturas intelectuais. Ao contrário, as habilidades cognitivas psicométricas são aglutinadas dentro da inteligência analítica, envolvendo basicamente processos de análise lógica, resolução de problemas abstratos e operações com linguagens e estruturas formais, entre outros componentes. A inteligência analítica, segundo Sternberg e Grigorenko (2003), é fortemente correlacionada às competências acadêmicas escolares. 
A inteligência prática assim concebida implica desconsideração e, em alguns casos, desobediência ao trabalho prescrito no todo ou em parte, bem como a conhecimentos técnicos e científicos; por isso, Dejours a chama inteligência ardilosa, pois aqui o pensamento zomba do rigor, uma vez que precisa simplificar a complexidade da realidade para poder formalizar os procedimentos. É o reino da malícia, da esperteza, da astúcia, do pensamento rápido, que é também o terreno dos automatismos dos especialistas com alto nível cognitivo. No caso pesquisado, há riqueza de relatos sobre essa desobediência, apontada em muitas situações como a condição que resolveu problemas e evitou acidentes.

Embora a inteligência prática seja fundamentalmente corpórea, não implica ausência do pensamento, não obstante conduza a modelações práticas e representações metafóricas do conhecimento técnico que não correspondem a cálculos ou aplicações rigorosas de procedimentos e instruções (idem, p. 288290).

A inteligência prática está mais vinculada à obtenção de resultados do que ao conhecimento declarativo dos princípios e processos que servem de caminho ao pensamento; a questão posta é resolver rapidamente o problema com economia de esforço e de sofrimento do corpo.

Finalmente, observa o autor, a inteligência ardilosa é criativa, fazendo surgir respostas, materiais, ferramentas e processos novos; e faz-se presente em todos os homens, desde que estejam em boas condições gerais, principalmente de saúde. Ela está presente no trabalho intelectual: "encontra-se também no centro da atividade intelectual, e mesmo do trabalho teórico... na atividade do pesquisador... a engenhosidade, os ardis da inteligência, [...] fazem-se notar na arte da demonstração, nas malícias, na elegância, às vezes no estilo, que se conjugam na parte retórica de todo discurso teórico e científico" (idem, p. 289).

Uma segunda forma de conhecimento tácito identificada por Jones e Wood é aquela que demanda diferentes graus de tomada de consciência para tomar decisões em situações que fogem à normalidade; dependendo da complexidade da situação a ser enfrentada, são diferentes os níveis de consciência a mobilizar, podendo ocorrer necessidade de processos cognitivos bastante complexos. Essa forma de conhecimento tácito foi observada, no caso pesquisado, entre os supervisores da operação, cujo perfil se caracteriza pela experiência e pelo tempo de atuação; o conhecimento teórico não é condição para exercer a função, embora todos tenham evidenciado relação com o conhecimento por um curso técnico ou um curso superior incompleto no passado, mas na maioria dos casos não aderente ao trabalho. Esses dados levamnos a concluir que, nesses casos, a formação sistematizada por meio de cursos contribuiu mais para desenvolver a capacidade de análise, de síntese, enfim de raciocínio lógico formal do que pelo acesso a conhecimentos científico-tecnológicos. Quando há situações de anormalidade, são os supervisores que decidem, a partir das informações dos operadores, os quais também contribuem para a operacionalização das decisões no plano das ações. Os operadores não decidem; reportam-se sempre aos operadores quando há uma dificuldade a enfrentar.

E, finalmente, apontam a terceira dimensão, que passa a desempenhar papel fundamental no toyotismo: as competências tácitas de natureza coletiva, derivadas da cooperação (Jones \& Wood, 1984, p. 6). Essa dimensão incorpora, segundo os autores, a tomada de consciência e julgamento dos trabalhadores sobre como se insere o seu trabalho no processo de produção, considerando as interfaces com os trabalhos de seus companheiros de equipe.

Essa dimensão leva à necessidade da análise das relações que se estabelecem entre os conhecimentos tácitos no âmbito do trabalho coletivo, com suas diferenciações a partir de uma hierarquização reordenada pela mundialização do capital e pela reestruturação produtiva. Nesse contexto, a combinação desigual entre trabalhos com diferentes níveis de qualificação/ precarização ao longo das cadeias produtivas é constituinte da natureza dos processos de flexibilização. Se o setor reestruturado se alimenta do precarizado para assegurar competitividade, prevalecendo a lógi- 
ca da polarização das chamadas competências flexíveis nos setores mais tecnologicamente complexos da cadeia produtiva, evidenciam-se diferentes combinações entre conhecimento tácito e científico, de modo que quanto mais se valoriza um tácito empobrecido, limitado por modelos de gestão fordistas, mais se precariza o trabalho (Kuenzer, 2003).

Decorre daí que a relação entre conhecimento científico e conhecimento tácito evidencia sua dimensão política, posto que se define a partir das possibilidades de diferentes combinações de estratégias de extração de mais-valia ao longo das cadeias produtivas. É essa dimensão que faz importante o conhecimento aprofundado dessa relação, quando se pretende desenvolver processos educativos comprometidos com a emancipação dos que vivem do trabalho.

\section{As relações entre trabalho, conhecimento e educação}

O segundo desafio posto pela pesquisa refere-se a como implementar programas de desenvolvimento de competências em um processo de trabalho no qual conhecimento tácito e científico se distribuem diferentemente entre os profissionais, de modo que se assegure a todos o direito ao acesso ao conhecimento a partir de suas necessidades e especificidades.

No caso em estudo, a análise das especificidades dos grupos que serão impactados de forma direta pela implantação da nova tecnologia mostra que, entre os operadores, predomina idade mais avançada, menos tempo de trabalho na planta e menos formação escolar ou formação não aderente à função, o que se compreende pela natureza mais específica, simplificada e repetitiva da tarefa. Pelos relatos, as atribuições dos operadores demandam conhecimento tácito pouco sofisticado para executar trabalho pouco complexo; dificilmente tomam decisões, recorrendo ao supervisor na maioria das vezes, portador de conhecimentos tácitos mais complexos que lhe permitem solucionar eventos; os operadores não relatam enfrentamento de emergências em que sua atuação fosse predominante. Ou seja, apresentam perfil pouco aderente às necessi- dades derivadas da implantação de inovações tecnológicas. Contudo, como já se afirmou anteriormente, revelam significativo conhecimento tácito, relevante para a implantação de novas tecnologias, embora nem sempre reconhecido em decorrência do modelo de gestão adotado, o que explica a transferência das responsabilidades de decisão para níveis mais elevados.

Os trabalhadores da manutenção, por sua vez, apresentam perfil diferente: têm formação aderente à função, geralmente em curso técnico de nível médio realizado nos Centros Federais de Educação Tecnológica, e reportam relação mais estreita entre conhecimento científico e conhecimento tácito, resultante da permanente necessidade de enfrentar situações complexas derivadas da manutenção de equipamentos antigos, para os quais muitas vezes sequer há peças de reposição, gerando necessidade de desenvolvimento de ferramentas e peças na própria planta. $\mathrm{Ou}$ seja, o trabalhador da manutenção exercita permanentemente sua capacidade de enfrentar situações não previstas que demandam soluções criativas, com o que é instado a buscar apoio no conhecimento científico disponível nos manuais, nos procedimentos, nos fornecedores, na Internet ou em especialistas.

Em síntese, as entrevistas, tendo em vista a proposição de propostas pedagógicas a partir das relações entre processo de trabalho, conhecimento, escolaridade e experiência, revelam que:

a) há diferenças significativas na relação entre conhecimento tácito e conhecimento sistematizado entre os que concluíram curso técnico aderente à sua área de trabalho e os que não o fizeram; ou seja, formação tecnológica aderente ao trabalho favorece o desenvolvimento de conhecimento tácito mais integrado ao conhecimento científico;

b) nos casos em que essa aderência não se confirma, verifica-se que a contribuição mais expressiva da formação escolar reside no desenvolvimento de competências cognitivas complexas, de modo especial as relativas ao domínio das linguagens e ao raciocínio 
lógico-formal, o que permite novas aprendizagens que acabam por favorecer a relação entre conhecimento científico e conhecimento tácito;

c) a dinamicidade e a complexidade do trabalho conduzem a uma relação mais estreita entre conhecimento tácito e científico; quanto mais dinâmico e complexo o trabalho, ou seja, quanto mais situações que fogem da normalidade (eventos) ele produz, mais impacta a relação entre conhecimento tácito e científico, levando o trabalhador a buscar os fundamentos de sua experiência para criar soluções inovadoras; ao contrário, o trabalho simplificado, repetitivo, leva ao desenvolvimento de um conhecimento tácito pouco complexo, fundado na prática, suficiente para resolver situações rotineiras e de baixa complexidade;

d) a conclusão do ensino médio em cursos de educação geral, na modalidade regular e supletivo, não evidenciaram, no caso pesquisado, favorecer a relação entre conhecimento tácito e científico; este dado precisa ser aprofundado por novas pesquisas, mas temos como hipótese que isso se dá antes pela desqualificação dessas modalidades do que pelo conteúdo com o qual trabalham; ou seja, não é a natureza geral do conteúdo que dificulta a relação entre conhecimento tácito e científico, mas sim seu caráter genérico, sem qualidade. Ao contrário, a pesquisa evidenciou, mais uma vez, que a relação entre conhecimento tácito e científico se faz pela mediação dos fundamentos científicos básicos mais do que pelo domínio de formas tecnológicas específicas que vão sendo superadas ao longo do tempo. Ou seja, a transferibilidade entre conhecimentos é mediada predominantemente pelo domínio dos fundamentos da ciência, da tecnologia e da sócio-história;

e) a realização de curso de formação na empresa, com foco no conhecimento teórico-prático do trabalho, pouco freqüente no caso em estudo, impacta significativamente a relação entre conhecimento tácito e científico, facilitando a articulação entre teoria e prática;

f) os entrevistados que evidenciam relação mais orgânica entre conhecimento tácito e científico apresentam melhores condições de qualificação em ciência e tecnologia, caracterizando um significativo diferencial para os que realizaram cursos técnicos nos Centros Federais de Educação Tecnológica ou cursos superiores na área tecnológica.

Essas conclusões, aliadas a outros resultados que temos obtido em pesquisa, indicam que a proposição de projetos pedagógicos que tenham por finalidade o desenvolvimento de competências com o intuito de implantar tecnologias de base microeletrônica em processos de trabalho nos quais conhecimento tácito e científico se distribuam diferentemente entre os profissionais supõe a compreensão da competência no espaço laboral como resultante da articulação entre teoria e prática no interior das práticas coletivas. Ao mesmo tempo, levam a considerar que a aprendizagem das novas tecnologias, particularmente de base microeletrônica, se dá de forma mais qualificada quando há experiência anterior de trabalho de campo.

Desse modo, os trabalhadores que têm conhecimento tácito, por transferência de aprendizagens anteriores, capacitam-se melhor e mais rapidamente para as novas tecnologias, desde que tenham suas competências cognitivas complexas desenvolvidas, o que conduz à proposição da seguinte estratégia pedagógica: desenvolver as competências com foco na equipe, uma vez que as pesquisas anteriormente realizadas no setor petroquímico e os dados levantados neste trabalho evidenciam que o enfrentamento das situações complexas é sempre resultado do trabalho coletivo, posto que demandam a articulação de diferentes conhecimentos e experiências, que contribuem, de modos diferenciados, para a solução de eventos, compreendidos como as ocorrências imprevistas, inesperadas, parcial ou totalmente, que perturbam o desenvolvimento regular da produção e não podem ser resolvi- 
das pelas próprias máquinas por meio de sistemas de autocontrole (Zarifian, 2001, p. 41-43).

A prática tem mostrado que, embora o horizonte a ser atingido seja o desenvolvimento de todas as competências, das mais simples às mais complexas, pela totalidade dos trabalhadores, $\mathrm{o}$ acesso ao conhecimento e às experiências laborais é diferenciado, de forma mais significativa nos países em que as desigualdades sociais são mais acentuadas.

Em decorrência, são necessárias duas ordens de ação, que compõem a estratégia de formação a ser adotada: a primeira, elevar a qualificação de toda a equipe, partindo da realidade de cada trabalhador; a segunda, organizar equipes de trabalho que sintetizem a competência coletiva demandada pelo trabalho, desde as mais simples até as mais complexas. Assim, em cada equipe deverá estar contemplada a capacidade de enfrentar situações complexas usando conhecimento e experiência, a capacidade de reflexão teórica mais avançada, o conhecimento tácito, a capacidade operacional, mas sem que sejam limitados os horizontes de capacitação de cada um de seus membros, segundo seu desejo e sua necessidade.

Para tanto, os processos pedagógicos deverão articular formação inicial visando ao resgate da capacidade de trabalhar intelectualmente por meio do domínio das linguagens, da matemática e dos conhecimentos básicos das ciências que fundamentam o processo de trabalho em tela, seguida de módulos de formação cada vez mais avançada, a serem cursados pelos trabalhadores sem que se estabeleçam limites prévios em função da natureza da ocupação. A perspectiva que fundamenta esta proposta, portanto, é o direito de todos ao conhecimento, a partir do reconhecimento das diferenças de acesso produzidas pelas desigualdades que decorrem, como dimensão estrutural, das relações entre capital e trabalho.

\section{À guisa de conclusão: a função mediadora dos processos educativos}

As novas relações entre conhecimento tácito e conhecimento científico a partir das mudanças decor- rentes da base microeletrônica trazem novos desafios para a educação dos que vivem do trabalho.

O ponto de partida para esta discussão é a constatação de que, de posse do conhecimento científico, o conhecimento tácito pode mudar de qualidade; a recíproca, porém, não é verdadeira, como apontam os operadores entrevistados na pesquisa já citada (Kuenzer, 2002, p. 8), que passam a reivindicar conhecimento científico para melhor responder aos eventos, constatando que sua prática não é suficiente; ou seja, a prática por si não ensina, a não ser pela mediação da ação pedagógica. São os processos pedagógicos intencionais e sistematizados, portanto, que, mediando as relações entre teoria e prática, ensinarão a conhecer. Portanto, não basta inserir o trabalhador na prática para que ele espontaneamente aprenda:

\section{[...] é preciso considerar que a prática não fala por si mes- ma; os fatos práticos, ou fenômenos, têm que ser identifi- cados, contados, analisados, interpretados, já que a realida- de não se deixa revelar através da observação imediata; é preciso ver além da imediaticidade para compreender as relações, as conexões, as estruturas internas, as formas de organização, as relações entre parte e totalidade, as finali- dades, que não se deixam conhecer no primeiro momento, quando se percebem apenas os fatos superficiais, aparen- tes, que ainda não se constituem em conhecimento. (idem, ibidem)}

A realidade, as coisas, os processos são conhecidos somente na medida em que são "criados", reproduzidos no pensamento e adquirem significado; essa "re-criação" da realidade no pensamento é um dos muitos modos de relação sujeito/objeto, cuja dimensão mais essencial é a compreensão da realidade enquanto relação humano/social. Ou seja, o ato de conhecer não prescinde do trabalho intelectual, que é um movimento do pensamento que não se desenvolve espontaneamente, precisando ser aprendido:

[...] o ato de conhecer não prescinde do trabalho intelectual, teórico, que se dá no pensamento que se debruça sobre a realidade a ser conhecida; é neste movimento do pensa- 
mento que parte das primeiras e imprecisas percepções para relacionar-se com a dimensão empírica da realidade que se deixa parcialmente perceber, que, por aproximações sucessivas, cada vez mais específicas e ao mesmo tempo mais amplas, são construídos os significados. (idem, ibidem)

Ensinar a conhecer, enquanto capacidade de agir teoricamente e pensar praticamente, é a função da escola; esse aprendizado não se dá espontaneamente pelo contato com a realidade, mas demanda o domínio das categorias teóricas e metodológicas pelo aprendizado do trabalho intelectual.

As novas demandas de articulação entre conhecimento científico e conhecimento tácito reforçam a necessidade de ampliação crescente das oportunidades de acesso ao conhecimento com qualidade como condição necessária à inserção e à permanência nas relações sociais e produtivas para os que vivem do trabalho.

As pesquisas que vêm sendo realizadas no âmbito deste projeto permitem apontar com segurança que a inclusão, resolvido o problema da oferta de ocupações, só será possível mediante o domínio dos conhecimentos científicos, tecnológicos e sócio-históricos que estão na base de constituição da sociedade contemporânea, a serem viabilizados, no mínimo, por uma boa escolarização fundamental e média. A partir daí, será possível, no trabalho ou em cursos de formação escolar, desenvolver competências de cunho mais específico para atender a demandas específicas do trabalho e da participação social.

\section{Referências bibliográficas}

DEJOURS, Chistophe. Inteligência operária e organização do trabalho: a propósito do modelo japonês de produção. In: HIRATA, Helena. Sobre o modelo japonês. São Paulo: EDUSP, 1993. p. 281-309.

JONES, Bryn; WOOD, Stephen. Qualificações tácitas, divisão do trabalho e novas tecnologias. Sociologia du travail, n. 4, p. $407-$ 421, 1984.

KUENZER, Acácia Zeneida. Conhecimento e competências no trabalho e na escola. Boletim Técnico do SENAC, Rio de Janeiro, v. 28 , n. 2, p. 45-68, maio/ago. 2002.
As relações entre conhecimento tácito e conhecimento científico a partir da base microeletrônica: primeiras aproximações. Educar em revista, Curitiba, v. especial, n. 10, p. 1333, 2003.

LLORI, Michel. Acidentes industriais: o custo do silêncio. Rio de Janeiro: Multiação, 2001.

SABÓIA, João. A dinâmica da descentralização industrial no Brasil. In: ENCONTRO DE ECONOMISTAS DE LÍNGUA PORTUGUESA, 4., Évora, 2001. Anais... Évora: s.ed., 2001. 1 CDROM.

SCHON, Donald. A. The reflective practitioner: how professionals think in action. Nova Iorque: Basic Books, 1983.

STERNBERG, Robert J.; GRIGORENKO, Elena L. Inteligência plena: ensinando e incentivando a aprendizagem e a realização dos alunos. Porto Alegre: Artmed, 2003.

ZARIFIAN, Philippe. Objetivo competência: por uma nova lógica. São Paulo: Atlas, 2001.

ACÁCIA ZENEIDA KUENZER, doutora em educação pela Pontifícia Universidade Católica de São Paulo (PUC-SP), é professora titular aposentada da Universidade Federal do Paraná (UFPR), na qual continua atuando no Programa de Pós-Graduação em Educação. Entre suas publicações recentes, destacam-se: A educação profissional nos anos 2000: a dimensão subordinada das políticas de inclusão (Educação \& Sociedade, Campinas, v. 27, n. 96, especial, p. 877-910, out. 2006); Competência como práxis: os dilemas da relação entre teoria e prática na educação dos trabalhadores (Boletim Técnico do SENAC, Rio de Janeiro, v. 29, n. 1, jan./abr. 2003); KUENZER, A. e MORAES, Maria Célia. Temas e tramas da pósgraduação no Brasil (Educação \& Sociedade, Campinas, v. 26, n. 93, p. 1.341-1.362, set./dez. 2005). Pesquisadora do Conselho Nacional de Desenvolvimento Científico e Tecnológico $(\mathrm{CNPq})$ na área de Trabalho e Educação.E-mail: acaciazk@uol.com.br

CLAUDIA BARCELOS DE MOURA ABREU, doutora em educação pela Pontifícia Universidade Católica de São Paulo (PUC-SP), é professora adjunta da Universidade Federal do Paraná (UFPR) no Programa de Pós-Graduação em Educação. Entre suas publicações destacam-se: Reestruturação produtiva, trabalho e educação: as implicações para a qualificação profissional (Revista de Educação Pública, Cuiabá, v. 13, n. 24, p. 80-93, 2004); Mudanças no mundo do trabalho e qualificação profissional: um 
estudo de caso (In: CONGRESSO INTERNACIONAL EDUCAÇÃO E TRABALHO, Anais..., Aveiro, 2005. CD-ROM); ABREU, C. B. M. e LANDINI, Sonia. Trabalho docente: a dinâmica entre formação, profissionalização e proletarização na constituição da identidade (Quaestio - Revista de Estudos da Educação, Sorocoba, v. 5, n. 1, p. 17-26, 2003). Pesquisadora na área de Trabalho e Educação.E-mail: claudiabarcelos@ufpr.br

CRISTIANO MAURO ASSIS GOMES, doutor em educação pela Universidade Federal de Minas Gerais (UFMG), é professor adjunto na mesma universidade, no Departamento de Psi- cologia da Faculdade de Filosofia e Ciências Humanas. Entre suas publicações destacam-se: Apostando no desenvolvimento da inteligência: em busca de um novo currículo educacional para o desenvolvimento do pensamento humano (Rio de Janeiro: Lamparina, 2007); O programa de desenvolvimento da lógica-formal: conceitos e estrutura (Educação em Foco, Belo Horizonte, v. 8, p. 13-20, 2005). Participa dos grupos de pesquisa Inovar e Neuropsicologia e Desenvolvimento Humano.E-mail: cristianogomes@ufmg.br

Recebido em maio de 2007 Aprovado em julho de 2007 
petroquímico brasileiro, analisa o processo de mudança tecnológica em ambiente de trabalho cujas operações demandam majoritariamente conhecimentos tácitos. A inovação proposta impõe reorganização da qualificação da força de trabalho, considerando o uso intensivo de tecnologia microeletrônica dos novos equipamentos e a demanda de conhecimentos científicos por parte dos operadores. Os dados foram coletados por meio de entrevista semi-estruturada com 91 trabalhadores das áreas de operação, manutenção e administração e evidenciam que os conhecimentos tácitos estão diretamente relacionados à complexidade do processo de trabalho, o que gera, para o processo de qualificação, necessidades diferenciadas de formação científica e tecnológica. Também foi possível constatar que os conhecimentos relativos à educação formal dos trabalhadores, quando converge com as exigências das atividades executadas por eles, tendem a facilitar a articulação dos conhecimentos tácitos e científicos. Os dados encontram respaldo em estudos anteriores realizados em processos de reestruturação produtiva.

Palavras-chave: conhecimento tácito e inovação tecnológica; formação para o trabalho; trabalho e educação

The articulation between tacit knowledge and technological innovation: the mediating function of education

This research, carried out in the Brazilian petrochemical sector, analyses the process of technological change in the work environment whose operations require chiefly tacit

Acácia Zeneida Kuenzer, Claudia Barcelos de Moura Abreu e Cristiano Mauro Assis Gomes

A articulação entre conhecimento tácito e inovação tecnológica: a função mediadora da educação Esta pesquisa, realizada no setor knowledge. The proposed innovation imposes a reorganization of the qualification of the work force, taking into account the intensive use of microelectronic technology of the new equipments and the demand for scientific knowledge by the operators. Data was collected by means of semi- 
structured interviews with 91 workers from the areas of operation, maintenance and management and revealed that tacit knowledge is directly related to the complexity of the work process which generates differentiated needs of scientific and technological training for the qualification process. It was also possible to confirm that when the workers' knowledge acquired in the processes of formal education converges with the demands of activities which they execute, it tends to facilitate the articulation between tacit and scientific knowledge. The data is supported by previous studies carried out in processes of productive restructuring.

Key words: tacit knowledge and technological innovation; training for work; work and education

La articulación entre conocimiento tácito e innovación tecnológica: la función mediadora de la educación Esta pesquisa, realizada en el sector petroquímico brasileño, analiza el proceso de cambios tecnológicos en ambiente de trabajo cuyas operaciones demandan mayoritariamente conocimientos tácitos. La innovación propuesta impone reorganización de la calificación de la fuerza de trabajo, considerando el uso intensivo de tecnología microeletrónica de los nuevos equipamientos y la demanda de conocimientos cientificos por parte de los operadores. Los datos fueron obtenidos a través de entrevista semi estructurada con 91 trabajadores de las áreas de operación, manutención y administración y prueban que los conocimientos tácitos están directamente relacionados a la complejidad del proceso de trabajo, lo que genera, para el proceso de calificación, necesidades diferenciadas de formación científica y tecnológica. También fue posible constatar que los conocimientos relativos a la educación formal de los trabajadores, cuando converge con las exigencias de las actividades ejecutadas por ellos, tienden a facilitar la articulación de los conocimientos tácitos y científicos. Los datos encuentran respaldo en estudios realizados anteriormente en procesos de reestructuración productiva.

Palabras claves: conocimiento tácito e innovación tecnológica; formación para el trabajo; trabajo y educación 